\title{
Implantation of a stent in a stenotic conduit between the left ventricle and aorta in a patient undergone surgery for a double outlet right ventricle
}

\author{
Sophie Samyn, Marielle Morissens, Ahmed Sanoussi, José Castro Rodriguez \\ Department of Adult Cardiology, CHU-Brugmann, Brussels, Belgium
}

\begin{abstract}
Reinterventions for surgery complications in adult patients with complex congenital heart disease are often difficult and have a high operative risk. If anatomically possible, a percutaneous approach is an alternative to surgery. We report the case of a 36 year-old patient who underwent surgery for a double outlet right ventricle with transposition of the great arteries and pulmonary stenosis. On the days following the surgery, the patient was hemodynamically unstable due to a stenosis of the intraventricular Dacron conduit between the left ventricle and the aorta. Because of the fragility of the patient, additional surgery was not possible and a percutaneous approach was preferred. A Cheatham Platinum stent mounted on a balloonin-balloon catheter was implanted with success in the stenotic intraventricular Dacron conduit.
\end{abstract}

Key words: congenital heart disease, balloon-in-balloon catheter, percutaneous approach

\section{INTRODUCTION}

A double outlet right ventricle (DORV) is a type of ventriculoarterial connection in which both great vessels arise entirely or predominantly from the right ventricle and the only outlet from the left ventricle is a ventricle septal defect (VSD). ${ }^{[1]}$ The relationship between the VSD and the great vessels considerably affects the choice of surgical technique. When possible, surgery consists of a biventricular repair with the construction of a channel between the left ventricle and the aorta performed in childhood. ${ }^{[2]}$ This is easily realized when the VSD is subaortic but more complex when the VSD is far from the aorta. ${ }^{[3]}$

\section{CASE REPORT}

A 36-year-old Bulgarian male presented with a DORV with transposition of the great arteries (TGA) and pulmonary stenosis (PS). His cardiopathy had not been completely corrected by surgery, but he underwent surgery for endocarditis at 12 years of age, which consisted of cleansing of the pulmonary vegetations, a commissurotomy of the PS, and an atrial septectomy. He was admitted to our cardiology unit for New York Heart Association (NYHA) class IV heart failure and chronic desaturation. The echocardiography showed a hypokinetic dominant right ventricle, transposed great arteries both arising from the right ventricle, a stenotic pulmonary valve with a peak gradient of $50 \mathrm{mmHg}$, a very large noncommitted VSD, and an atrial septal defect. Despite optimal medical treatment, the patient remained in NYHA class III and it was decided that surgical correction was necessary. Due to the noncommitted VSD, the surgeon had to use a Dacron conduit (Gelweave caliber, $26 \mathrm{~mm}$ ) to connect the left ventricle to the aortic valve through the right ventricle. The implantation of the conduit was particularly difficult because of the crossing of the tricuspid subvalvular apparatus. A composite conduit with pulmonary homograft was used to connect the right ventricle to the pulmonary artery. The atrial defect was closed with a GoreTex patch. 
On the days following the surgery, the patient was hemodynamically unstable and had to remain on mechanical ventilation. Transesophageal echocardiography showed the presence of a residual VSD near the junction of the intraventricular conduit and an acceleration of flow into the Dacron conduit. At that time, it was difficult to determine if the instability was due to the left to right shunt or the obstruction. To gain a better understanding, catheterization was necessary. A left ventriculography was performed with a graduated pigtail catheter $5 \mathrm{Fr}$ (Cook Medical, Indiana, USA) and it confirmed a shunt was present through the VSD. Moreover, the measured hemodynamic gradient into the Dacron conduit between the left ventricle and the aorta was $100 \mathrm{mmHg}$ due to a kinking of the conduit (Figure 1). Therefore, our hypothesis was that the obstruction in the conduit was responsible for an increase in the shunt through the residual VSD, and this led to low systemic flow.

After a discussion with the cardiac surgery team, it was decided that the patient was too unstable to undergo a risky and complex new surgery. We chose to treat the stenotic conduit using a percutaneous approach with a non-covered Cheatham Platinum (CP) stent directly after the diagnostic procedure. The length of the conduit was measured with the graduated pigtail as $45 \mathrm{~mm}$. An Amplatzer torqvue delivery sheath 12 Fr (Saint Jude Medical, Saint Paul, USA) was placed in the right femoral artery and an Amplatz super stiff wire (Boston Scientific, Natick, USA) was positioned in the left ventricle through the Dacron conduit. We mounted the $45 \mathrm{~mm}$ CP stent on a balloon-in-balloon (BIB) catheter (NuMED company, Hopkinton, NY) with a 24 $\mathrm{mm}$ diameter. The $\mathrm{CP}$ stent was placed under angiographic control; the inner balloon was inflated at 3 atmospheres; then, the outer balloon was inflated at 2 atmospheres with a good expansion of the CP stent (Figures 2-4). After the stent placement, a contrast injection in the left ventricle showed a decrease of the shunt through the residual VSD and the gradient in the conduit was reduced to $35 \mathrm{mmHg}$. Shortly after the procedure, the patient gradually improved and was removed from ventilation after 7 days.

\section{DISCUSSION}

We report the case of a patient who underwent surgery as an adult for a DORV with TGA and PS. The immediate postoperative period of this patient was marked by low systemic flow. The transesophageal echocardiography suggested a residual VSD and a gradient in the conduit between the aorta and the left ventricle. We performed catheterization and discovered a kinking of the intraventricular conduit, which was responsible for the low systemic flow due to the obstruction, and an increased shunt through a small residual VSD.
Because of the noncommitted VSD, the connection between the VSD and the aortic valve must be achieved using an intracardiac conduit instead of a patch (known as Kawashima intraventricular rerouting). ${ }^{[4,5]}$ Our patient was too fragile to undergo a new surgery and we thought the stenotic conduit could be easily accessed using a percutaneous approach. The intervention occurred directly after the diagnostic catheterization. The presence of the Dacron conduit allowed us to treat the obstruction with a $\mathrm{CP}$ stent mounted on a BIB catheter, which is composed

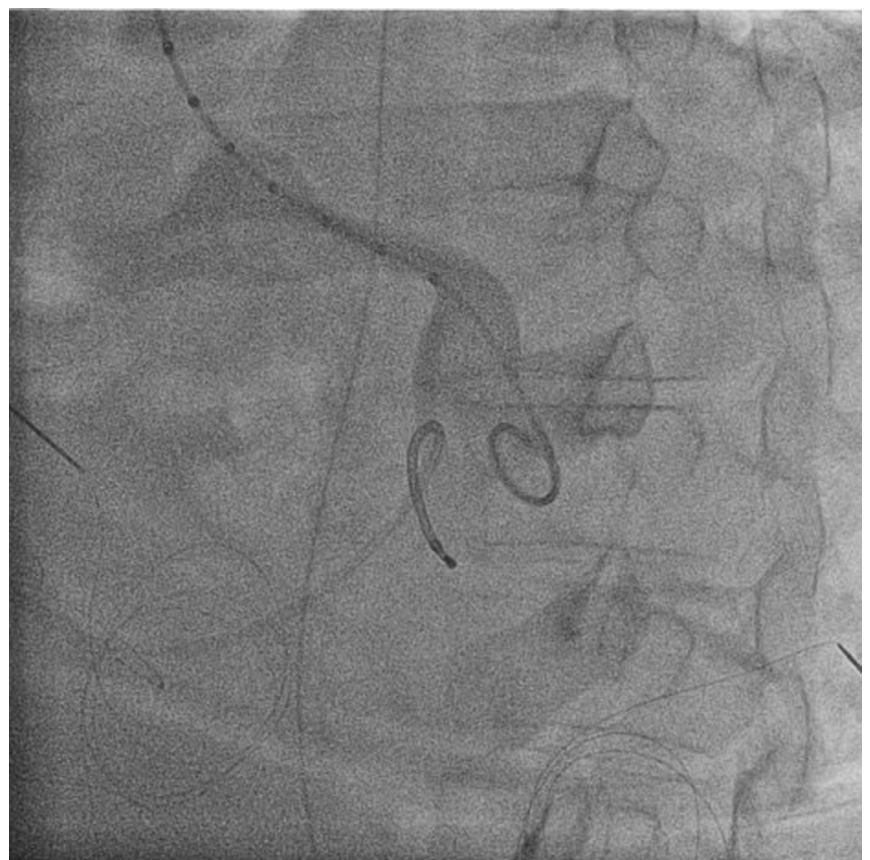

Figure 1: The kinked intraventricular Dacron conduit

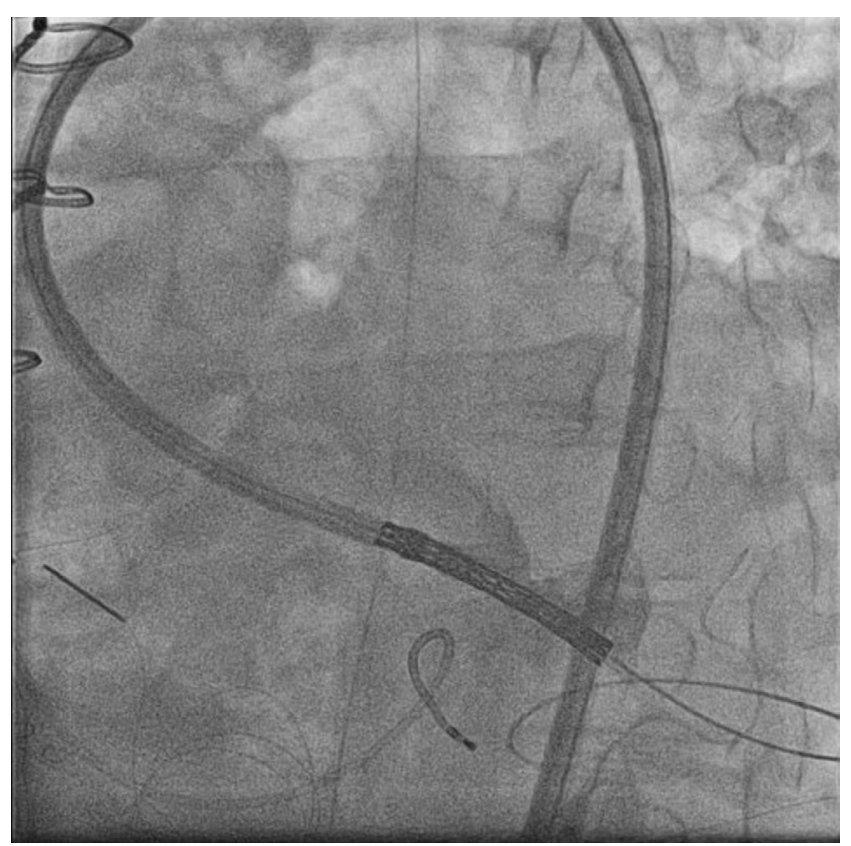

Figure 2: Implantation of the Cheatham Platinum stent under angiographic control 
(a)

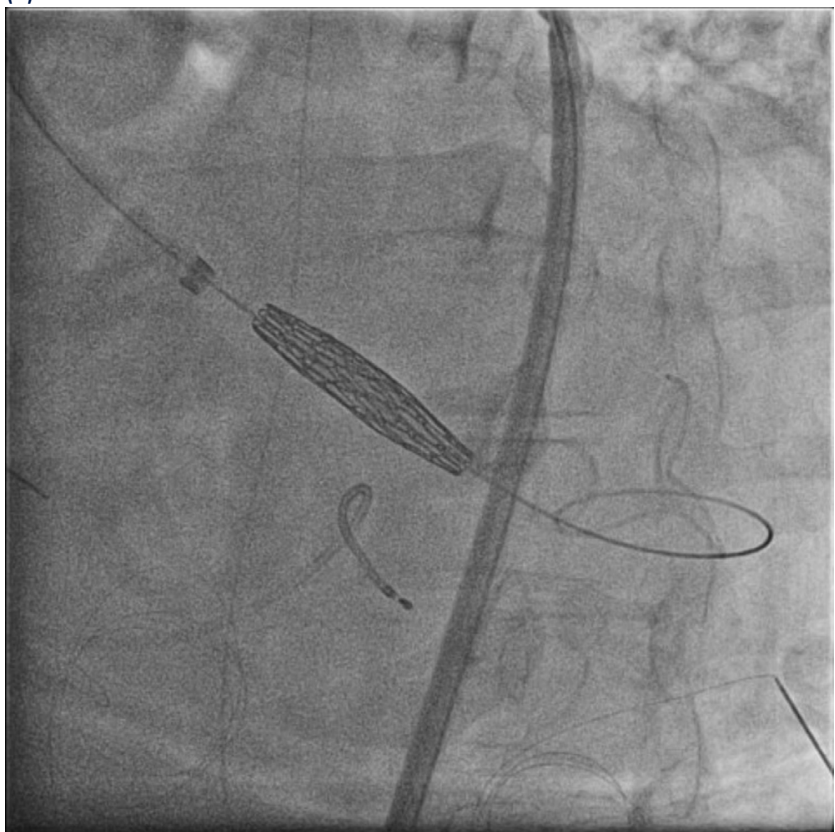

(b)

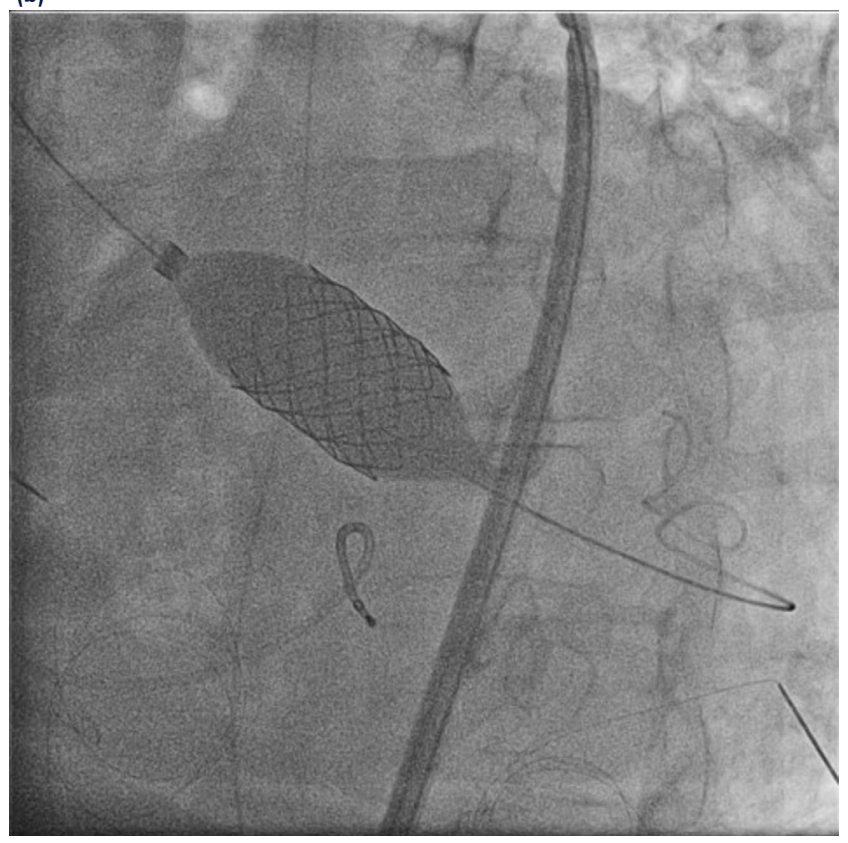

Figure 3: First the inner balloon was inflated (a); then, the outer balloon was inflated with good expansion of the Cheatham Platinum stent (b)

of an inner and an outer balloon. The inner balloon is inflated first and allows stabilization of the stent in difficult anatomical or hemodynamical situations. The inflation of the outer balloon leads to the final expansion of the $\mathrm{CP}$ stent. The CP stents are generally used to treat native or postoperative aorta coarctation in older children and young adults. ${ }^{[6,7]}$ The use of $\mathrm{CP}$ stents in other congenital heart diseases has been described, but not frequently. A CP stent was used to expand a cavopulmonary conduit and to treat a supra-PS after arterial switch intervention. ${ }^{[8]}$ To our knowledge, this is the first published case where a CP stent was implanted in an intraventricular conduit between the left ventricle and the aorta after surgery for DORV.

\section{Acknowledgements}

The authors wish to acknowledge Prof. Pierre Wauthy, Dr. Hélène Demanet, and Dr. Hugues Dessy for their contributions in treating this patient.

\section{Conflict of Interest}

There is no conflict of interest.

\section{REFERENCES}

1. Walters HL III, Mavroudis C, Tchervenkov CI, Jacobs JP, Lacour-Gayet F, Jacobs ML. Congenital Heart Surgery Nomenclature and Database Project: double outlet right ventricle. Ann Thorac Surg 2000;69:S249-63.

2. Rastelli GC, Wallace RB, Ongley PA. Complete Repair of Transposition of the Great Arteries with Pulmonary Stenosis. A Review and Report of a Case Corrected by Using a New Surgical Technique. Circulation 1969;39:83-95.

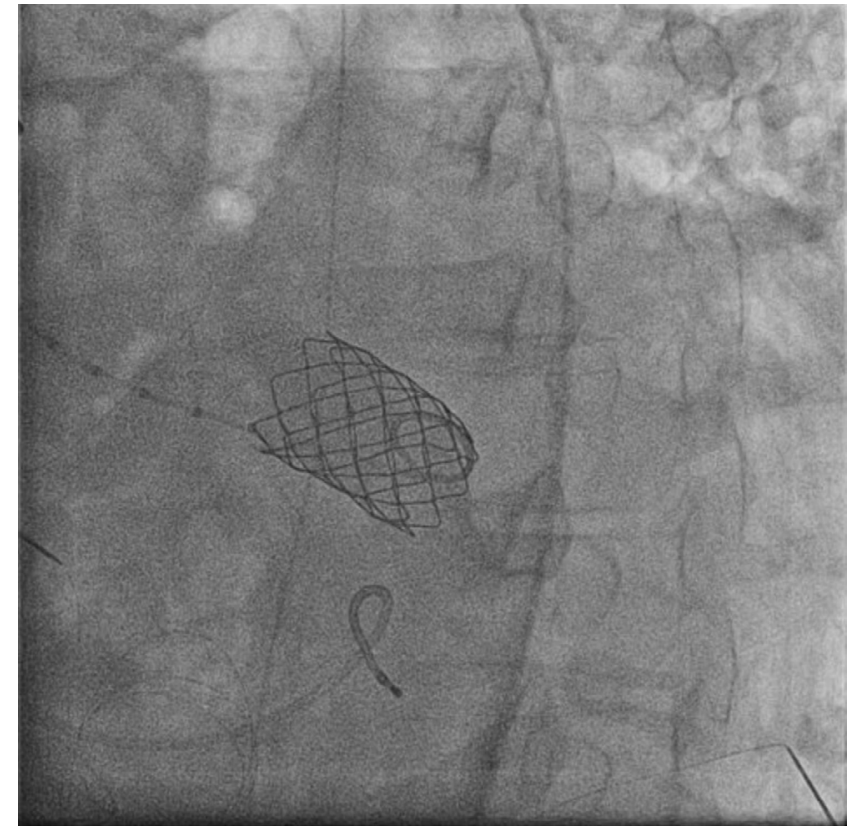

Figure 4: Angiographic control of the expanded Cheatham Platinum stent in the Dacron conduit

3. Q Wu, Q Yu, X Yang. Modified Rastelli Procedure for Double Outlet Right Ventricle with Left-Malposition of the Great Arteries: Report of 9 Cases. Ann Thorac Surg 2003;75:138-42.

4. Li S, Ma K, Hu S, Hua Z, Yan J, Pang K, et al. Biventricular repair for double outlet right ventricle with non-committed ventricular septal defect. Eur J Cardiothorac Surg 2015;48: 580-7.

5. Kawahira Y, Yagihara T, Uemura H, Ishizaka T, Yoshikawa Y, Yoshizumi $\mathrm{K}$, et al. Ventricular outflow tracts after Kawashima intraventricular rerouting for double outlet right ventricle with subpulmonary ventricular 
septal defect. Eur J Cardiothorac Surg 1999;16:26-31.

6. Ringel RE, Vincent J, Jenkins KJ, Gauvreau K, Moses H, Lofgren K, et al. Acute outcome of stent therapy for coarctation of the aorta: Results of the coarctation of the aorta stent trial. Catheter Cardiovasc Interv 2013;82:503-10.

7. Ebeid MR, Prieto LR, Latson LA . Use of Balloon-Expandable Stent for coarctation of the Aorta: Initial Result and Intermediate-Term FollowUp. J Am Coll Cardiol 1997;30: 1847-52.
8. Vanagt WY, Cools B, Boshoff DE, Frerich S, Heying R, Troost E, et al. Use of covered Cheatham-Platinum stents in congenital heart disease. Int J Cardiol 2014;175: 102-7.

How to cite this article: Samyn S, Morissens M, Sanoussi A, Castro Rodriguez JC. Implantation of a stent in a stenotic conduit between the left ventricle and aorta in a patient undergone surgery for a double outlet right ventricle. J Transl Intern Med 2018; 6: 194-7. 